\title{
Implementation of a Computing Device to Quality Service in Learning in Higher Education to Enhance Student's Quality of Life
}

\author{
1,2 Mohssine Bentaib, ${ }^{1,2}$ Mohammed Aït Daouad, ${ }^{1}$ Bouzekri Touri, \\ ${ }^{2}$ Abdelouahed Namir, ${ }^{2}$ lhoucin Labriji, ${ }^{1}$ M'hammed El Kouali, \\ ${ }^{1}$ Mohammed Talbi \\ ${ }^{l}$ Observatoire de Recherche en Didactique et Pédagogie Universitaire (ORDIPU), \\ ${ }^{2}$ Laboratoire de Technologie de l'Information et de Modélisation \\ Université Hassan II Mohammedia-Casablanca, Faculté des Sciences Ben M'Sik, Maroc
}

\begin{abstract}
Summary: Our work is concerned with monitoring and periodic evaluation of students' skills acquired during their university education. The objective of our work is to provide software tools for supporting and mentoring students in order to improve their quality of life.

We suggest a computing device "ISIFePortfolio" which not only allows monitoring of learners, but also plays the role of an ePortfolio (electronic portfolio) skills, and a social networking combined systems. This tool includes a broad range of collaborative working solutions and the ePortfolio is considered an extension of the "paper" records of a student as an individual digital space available on the Internet in such a secure and personalized way, collecting personal resources, experiences, studies, acquired skills, relationships with trainers, working groups, classmates and that will be saved throughout the training course.

Based on Mahara technology, "ISIFePortfolio" is an application implemented by ORDIPU team at the University Hassan II Mohammedia - Casablanca. It has been integrated into the platform of distance education "Education Master ISIF" for the master "Engineering Information Systems and Training."
\end{abstract}

Keyword: computing device, ePortfolio, skills, digital monitoring of the learner, evaluation, quality of life.

\section{Introduction}

The use of e-portfolio in higher education has been a great technological innovation. For learners, the ePortfolio promotes learning, emphasizes the practice of reflective learning and engages learners to take a more active role in learning. For academics, the ePortfolio is an evaluation tool for both formative and summative assessment methods; it is a means to assess the achievements and progress of the learner over time.

The portfolio does not replace the formal qualification. Its purpose is to provide evidence of professional and personal skills of an individual or the learning experience gathered in a certain period of time.

However, the growing importance and benefits of ePortfolio system as a means to collect the achievements of students and to assess their progress also raises several issues of interoperability. For example, it is important that evidence of student work does not disappear or become unusable when they move to another institution. In this context, the interoperability specifications supported by both LMS and ePortfolio systems are part of the solution.

\section{Portfolio}

A portfolio is a systematic and determined collection of completion documentation and of work [1].

The portfolio is more than just a tool to record the professional and personal growth over time. The "Suitcasing" or the package of skills is not enough in this demanding information age where professional and personal skills are developed every day. EPortfolios have more advantages over printed portfolios being easily accessible, having the ability to store multiple media, is easy to update, and refers to the work of the learner [2]. Lin [3] examines the theoretical findings that support the development of ePortfolios as a learning strategy and as a tool for technical reflection. In higher education ePortfolio was used as an alternative assessment tool. In the principles of active learning, experiential learning is at the heart of the portfolio approach and promotes the use of portfolios for the purpose of assessment and personal development plan. Considering evaluation, Endacott and methods. al. [4] concluded that portfolios are systems under development, which affects the evaluation of the portfolio. The analyzed data revealed four approaches to the structure and use of portfolios: shopping trolley; toast rack; spinal column and cake mix. The four structures (Fig. 1) imply the effectiveness of portfolios in the assessment of learning and competence. 
The shopping cart "shopping trolley" is a repository of artefacts collected during the course. There is little obvious cohesion in the portfolio and little effort to link the evidence of results or learning skills. Toast rack "record" is composed of several distinct elements (toast) that assess different practical or theoretical aspects. These elements are separated even if the workbook acts simply as a convenient device to keep items in one place. There is no overall narrative to connect the different sections, and different people may participate in the evaluation. The portfolio itself may or may not be evaluated or considered.

"Spinal column" is structured around practical skills where learning results and evidence are inserted inside, to show how each skill is reached. Reflection accounts may consider more than one jurisdiction, and act as a liaison flesh. Emphasis is placed on the original work of the learner, while the evidence is used to support or illustrate the case made.

The cake mix approach "cake mix" is selected when the theoretical and practical evidence are included in the portfolio and the set (cake "cake") is evaluated. The narrative combines elements. Comment reflection aims to demonstrate the critical and analytical skills of learners by considering how they got what they have. The form of a "cake" is the sum of its individual parts and that is all that is evaluated rather than the ingredients. Reflectivity, practice and professional development are probably the features of this model.

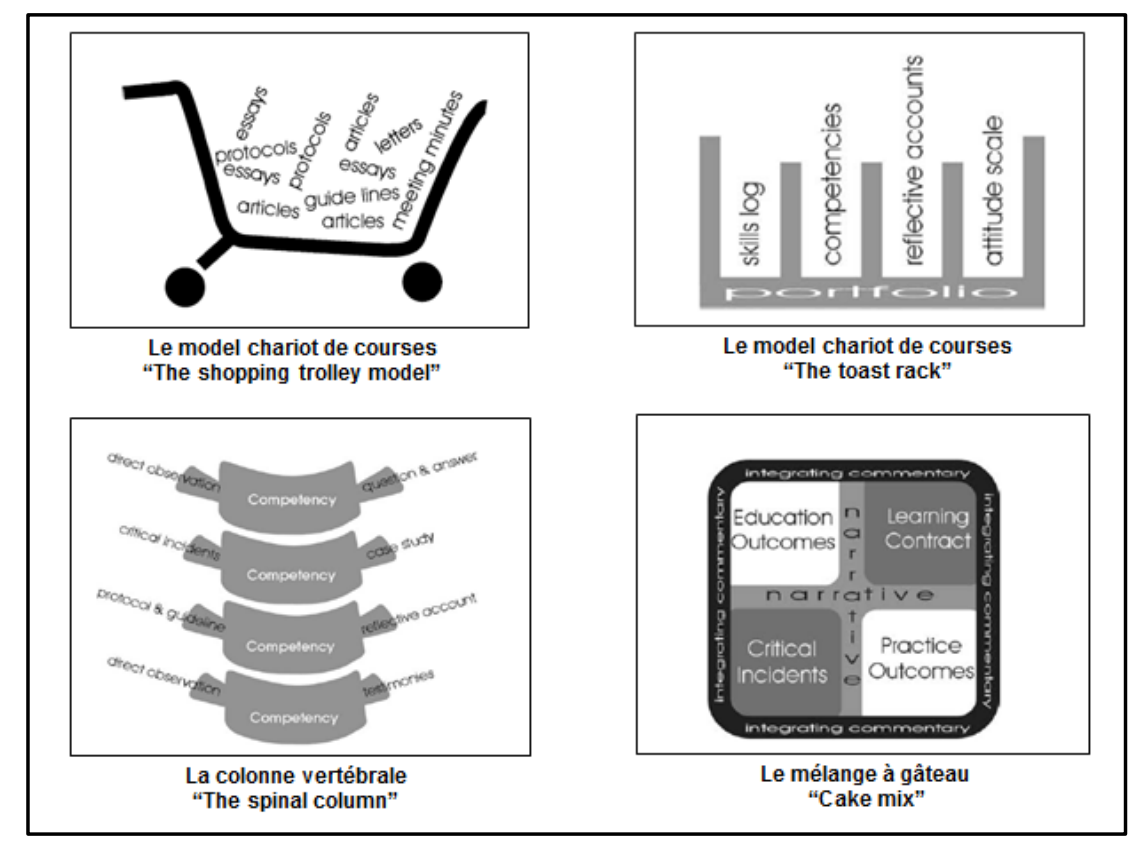

Fig. 1.Four portfolio models by Endacott et al. [4]

\section{Electronic Portfolio (Eportfolio)}

EPortfolios are highly customized. They are customizable files that are web-based that document and demonstrate individual and collaborative learning [5]. An ePortfolio system is a referential management system based on the web that stores student learning documents (known as the artefact name) such as school records, testing, project reports, homework, assessments and content related to personal and professional development. Students use ePortfolio systems to introduce artefacts, receive feedback from instructors and advisors, as well as communicate with each other.

According JISC [6], the construction of ePortfolio in the learning process helps to:

(a) improving the understanding of self and understanding of the curriculum;

(b) the commitment and motivation of students, both individually and as part of a community of practice;

(c) personalize learning;

(d) support the learning of appropriate models in the digital age;

(e) and the promotion of reflective practice.

These contributions are shared by students, teachers, parents and administrators. For students, it shows their achievements and encourages them to take responsibility for their work. For teachers, it provides a framework for organizing the work of students and facilitates the evaluation and decision making. For parents, it offers a glimpse of what their children are doing in school. 
There are many commercial ePortfolio like Chalk \& Wire [7], KEEP toolkit [8], foliotek [9], TaskStream [10], and other open-source (PSO) [11]. Although there are high variations in user interface design between the ePortfolio systems, their features remain the same, they include publishing artefacts and upload, comment and evaluate student work, ensure communication and sharing within groups, guarantee the generation of windows (showcase generating), as well as administrative reports.

EPortfolios are stored online and they have great accessibility for homeowners of portfolios themselves, teachers, colleagues and employers [12]; [13]; [14]. EPortfolios provide a mechanism for students and educational institutions to improve and demonstrate their teaching/learning knowledge, and show skills to society. [15]. EPortfolios Systems enable at all levels administrations to study and conduct comprehensive evaluation of teaching and learning performance [16].

In summary, the ePortfolio enables students to build a structured collection of knowledge, skills and competences [17]. It allows learners to follow the development of their thinking and learning over time and show their skills to both teachers and employers, providing essential digital resources to their own study (personalized information) and links towards other learners (for collaboration and feedback) [18].

\section{Strategies For Integration}

An LMS is a software designed for the administration, documentation, tracking, reporting training programs, online classes and events, and training content [19]. There are open source systems such as Moodle, Sakai, LRN or Dokeos, and commercial systems such as WebCT / Blackboard or Desire2Learn. Content delivered by an LMS can be created, obtained, collected or assessed in several types of systems such as directories of learning, ePortfolios systems, specialized evaluators or Quizzes objects.

An ePortfolio is a product created by the student that contains a collection of digital objects (artefacts), combining different media (audio / video / text / images) [20]. Its main objective is to gather evidence for the summative evaluation to demonstrate the achievements, record progress and set targets[21]. The main motivation for integrating an ePortfolio system into an LMS is used as a tool for assessing the skills of the student.

There are several integration of an ePortfolio system in a LMS strategies, but we will only present the most common strategies, namely:

- «Data integration",

- Integration Programming Interface "API "

• "Tool integration."

\section{A. "Data integration"}

Data integration is the simplest and most popular form of integration into content management. This type of integration uses the import / export features of both systems and relies on the support of common formats as shown in Fig. 2. Example, an ePortfolio system can import data (contributions blog and forum by students, course materials and assignments uploaded by teachers) from LMS to avoid the burden of entering data manually.

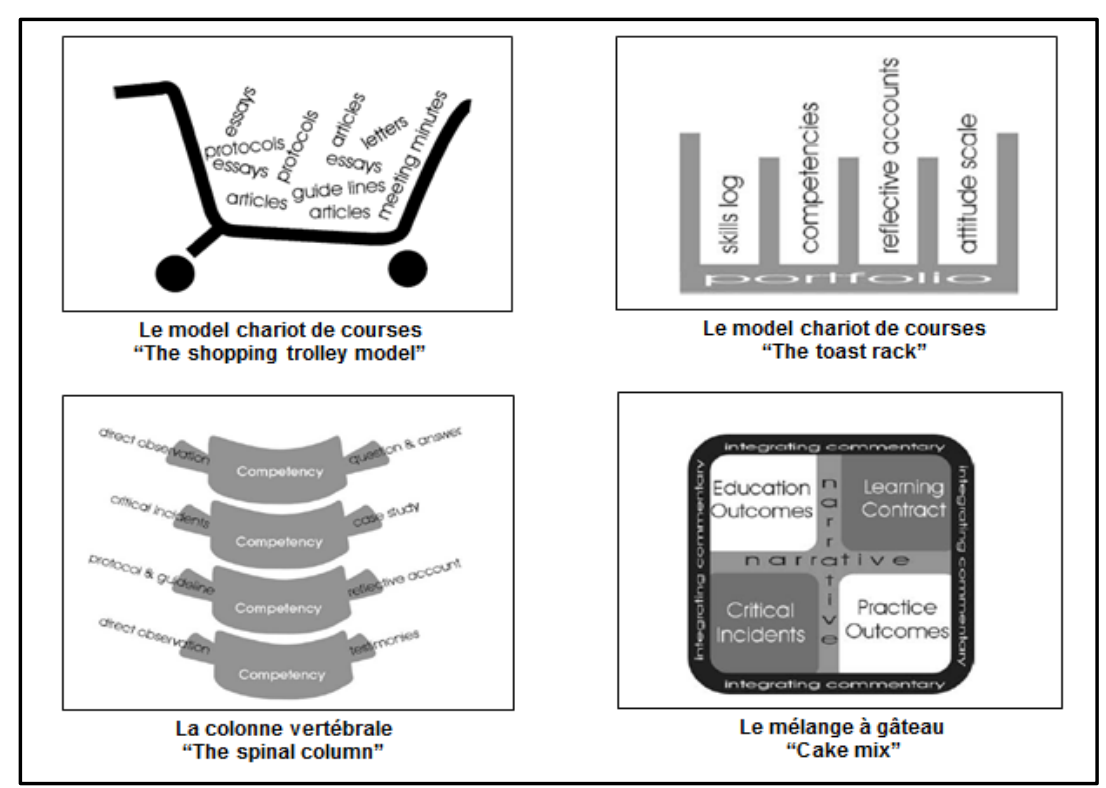

Fig.2. Data Integration 
These systems support two types of common formats: Generic (HTML files) and specific (files Leap2A [22]). The first is useful because it is widely available, but it lacks specific semantic data provided by the other format. For example, if we add a message in a Moodle forum should be included in the Mahara ePortfolio as a blog and not as a non-editable HTML artefact. This requires the use of a common standard of Mahara ePortfolio so that (or any other ePortfolio system) can understand the meaning of the content and decide its final format.

EPortfolio standards are widely used in several interoperability [23, 24, 25] and project [26, 27, 28] specification. One of these projects is PEACE (Project for ESEIG Academic Content Environment) This project aims to integrate an ePortfolio system (Mahara) with the LMS of the institution (Moodle) within a learning environment $[33,34,35]$. composed of several services targeting the new paradigm of Web 2.0 [17,28].

\section{B. "API Integration"}

An "Application Programming Interface (API)" allows application users to benefit directly the functions of an e-Learning system. These APIs encourage the development client data encapsulation and reuse of application behaviour. This clear separation of specification of their implementation of interfaces and data formats allows tool vendors to develop new versions without affecting existing customers [29].

The main suppliers of LMS include APIs to allow developers to expand their predefined characteristics through the creation of plug-ins. Blackboard uses "Building Blocks" technology to cover the problems of integration with other systems by allowing third party developers to develop modules using the "Building Blocks" API.

Moodle includes several APIs (Fig. 3) to allow developers of third party plug-ins to access folders and portfolios such as "Repository API [23]" for navigation and retrieval of files from external repositories; and "Portfolio API [24]" for exporting Moodle content on external repositories.

Both APIs are based on the file API which is a set of basic interfaces to allow Moodle to manage access control, store and retrieve files. The new API is designed to improve the management of files by avoiding redundant storage. This functionality is achieved because each file in Moodle is stored in a file pool (a directory in moodle) with a file name that is calculated as a SHA1 hash of the file content. If a file is copied, there is no duplication of files action happening, just a new record in a special table file is created.

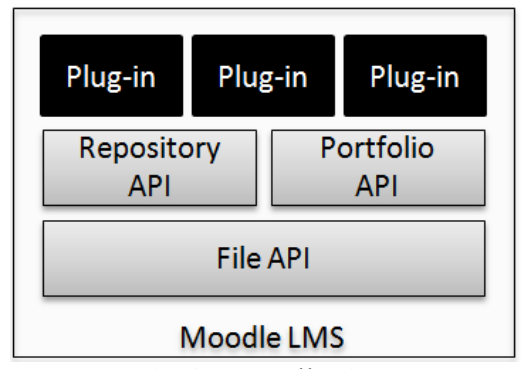

Fig.3. Moodle API

To ensure two-way communication between an LMS and ePortfolio system, it is necessary to use both APIs to create plug-ins.

\section{C. "Tool Integration."}

Learning tools interoperability IMS "IMS LTI (Learning Tools Interoperability)" provide an extension based on uniform standards LMS allowing remote tools and content to integrate into LMS systems. The main objective of the LTI is to standardize the process of building links between learning tools and LMS. There are several advantages of using this approach: educational institutions, LMS vendors and tool vendors can adhere to a clearly defined interface between the LMS and the tool. This will reduce costs, increase options for students and instructors in the selection of learning applications and also potentiate the use of software as a service "Software as a Service (SaaS)". LTI has three key concepts as shown in Fig. 4 [30]: the Supplier of the "Tool Provider", the Consumer Tool "Tool Consumer" and the Profile Tool "Tool Profile" tool. 


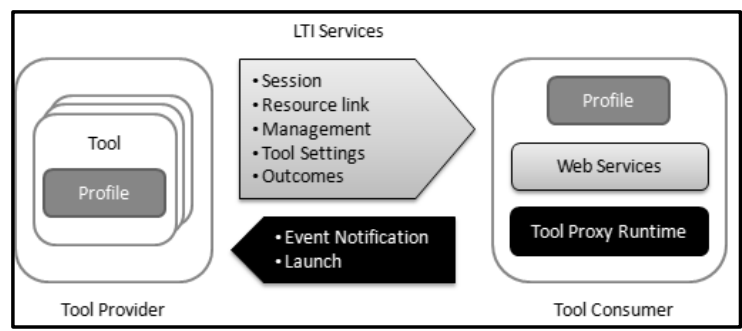

Fig. 4. IMS Learning Tools Interoperability

\section{Integration Of An Eportfolio}

In this section we present an example of integrating an ePortfolio system based on Mahara "ISIFePortfolio" technology (Fig. 5) in LMS Moodle. This application has been implemented by the team ORDIPU University Hassan II Mohammedia - Casablanca.

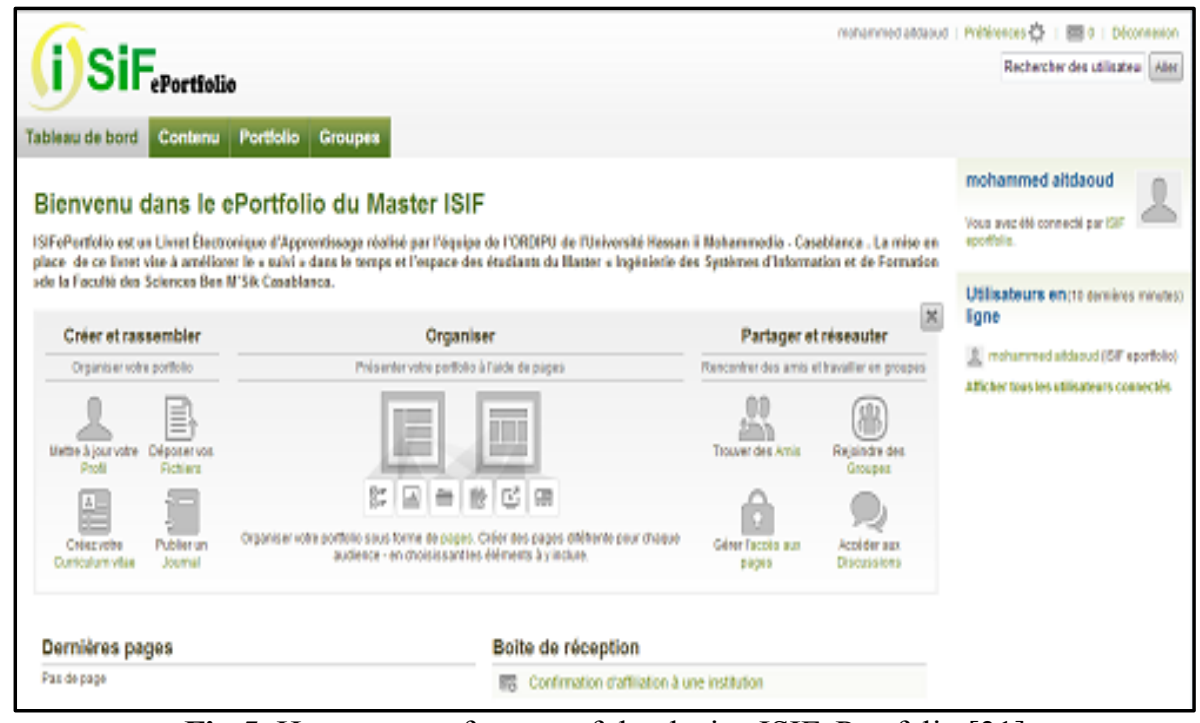

Fig.5. Home page of a user of the device ISIFePortfolio [31]

This case study is related to the social part of our research project which implements a platform for distance education "Education Master ISIF" to create a personal learning network "Personal Learning Networks (PLN) "for the benefit of students of master ISIF" Engineering Information Systems and Training. "It aims to integrate their personal learning environments (PLE) [33,35], ePortfolios, and LMS, as shown in Fig. 6 [17]. This environment is developed using an open source application to create ePortfolios and social networks Mahara "ISIFeportfolio" integrated with LMS Moodle.

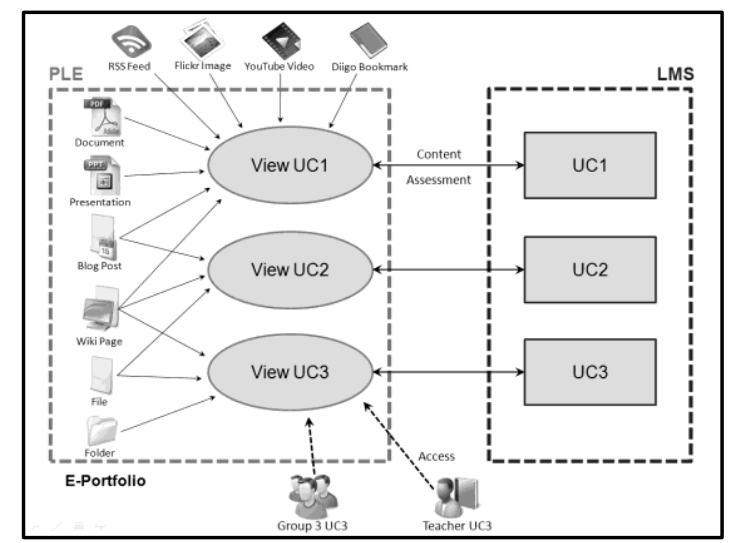

Fig.6. Intégration of an ePortfolio, PLE and LMS [17]

Moodle and Mahara share the student profile, so it has a unique set of authentication data (login and password) on both applications (Single Sign On). Thus, a student authenticated in Moodle can automatically 
access his profile Mahara without having to reconnect. If the student has not yet created a profile in Mahara, it is created automatically during the first access on his data profile Moodle.

We have integrated both Moodle and Mahara systems based on the first two strategies mentioned in the part of integration strategies in order to achieve the following objectives:

Our first objective is to allow a student who needs to export a single resource (eg, work in PDF format) Moodle to a specific view in his ePortfolio Mahara. Given the sporadic nature of this case, we chose the data integration strategy. In this strategy file sharing is based on the import / export features of both systems. In this case, the student exports the resource in its native format from Moodle and imports the same resource in Mahara. Both systems support a wide range of file formats such as HTML, PDF, image and video formats.

Our second objective is to establish a mechanism to export periodically (eg annually) all students work to their ePortfolio Mahara. The purpose of this export is twofold: 1) to have academic work produced in Moodle organized by student rather than per course; 2) encouraging students to maintain their own portfolios by feeding it with the work they have done in Moodle. In this scenario, we use the integration on a batch mode since any manual interaction / graphic would be tedious and error-prone. This is a clear case of the integration strategy of the API because it is the only one that supports batch communication. This is achieved by substituting prepare_package and send_package methods of the portfolio_plugin_base class included in the API. Method "prepare_package" prepares the package for submission, writing metadata files and compress all the files in a temporary folder. The second method "send package" sends the package to a remote system based on a request from XMLRPC. A script calling these methods in order is periodically invoked by Cron. [31]

\section{Conclusion}

In recent years ePortfolios have been used in higher education as an alternative assessment tool. Despite the diversity of their structure and use, ePortfolios are ways of presenting the competence of the learner and as a tool for personal development planning. The use of an ePortfolio to maintain a record of achievement allows the learner to reflect on the experiences and chart a course to develop skills, improve quality of life which will also help in planning the path of his career.

This paper presents and compares three strategies for integrating an ePortfolio system into an LMS, namely Data Integration, API Integration and Tool Integration. As part of our research we were able to integrate the system with the Mahara LMS Moodle using two strategies: Data integration et API Integration. This allowed us to browse and retrieve files from the LMS Moodle and integrate them in Mahara and vice versa. Thus, it was possible to implement the integration on a batch mode to automate the copy of student work in Moodle "Training Master ISIF" to their ePortfolio Mahara "ISIF ePortfolio."

\section{References}

[1] H. N. Drier, "Career portfolios - Don't leave home without one," Career Planning \& Adult Development Journal, 12(4), 55-60, pp. 1997.

[2] Johnsonetal. "Developing portfolios in education: Aguidetoreflection,inquiry,and assessment," San Francisco: SAGEPublications, 2006.

[3] Lin,Qiuyun, "Preserviceteacherslearningexperiencesofconstructinge-portfoliosonline," TheInternetandHigherEducation.vol. 11,3-4, pp. 194-200, 2008.

[4] R.Endacott,etal. "Usingportfoliosintheassessmentoflearningandcompetence:theimpactof fourmodels,"Nurse Educationin Practice, vol. 4, pp. 250-257, 2004.

[5] C. McCowan, W. Harper, \& K. Hauville, "Student e-portfolio : The successful implementation of an e-portfolio across a major Australian university". Australian Journal of Career Development, vol. 14(2), pp. 40-52, 2005.

[6] JISC, "Effective Practice with e-Portfolios: Supporting 21st century learning," Online]. Available: http://www.jisc.ac.uk/media/ documents/ publications/effectivepracticeeportfolios.pdf

[7] CW. Chalk \& Wire. (2009). Retrieved February 4, 2009 from http://www.cha lkandwire.co m/eportfolio

[8] KEEP.(2009).KEEPtoolkit.SRetrievedFebruary15,2009fromhttp://www.cfkeep.org/static/indexhtml

[9] Foliotek.(2009). “folioteke-portfoliosystem,"RetrievedFebruary5,fromhttp://www.foliotek.com/

[10] TaskStream.(2009). “TaskStreame-portfoliosystem,"RetrieedFebruary12,[Online]. Available /https://www.taskstream.com/pub/

[11] OSP.(2005). “Open-SourcePortfolio,”Whitepaper:UnderstandingOSP.RetrievedFebruary15,[Online]. Available :http://www.rsmart. com/ assets/ understandingOSP_Dec2005.pdf

[12] I. Bruder, "Alternative assessment: Putting technology to the test," Electronic Learning, vol. 12, pp. 12-28, 1993.

[13] K. Bushweller, "The high-tech portfolio," The Executive Educator, vol. 17, pp. 19-22, 1995.

[14] C. McCowan, W. Harper, \& K. Hauville, "Student e-portfolio : The successful implementation of an e-portfolio across a major Australian university," Australian Journal of Career Development, vol. 14(2), pp. 40-52, 2005.

[15] J. A. Lumsden, J. W. Garis, R. C. Reardon, M. P. Unger, \& S. Arkin, “A blueprint for building an online career portfolio,” Journal of Career Planning and Employment, 62(1), 33-38, pp. 2001.

[16] H. C. Barrett, "Technology-supported assessment portfolios," The Computing Teacher, vol. 21, pp. 9-12, 1994.

[17] L. Oliveira, \& F. Moreira, "Personal Learning Environments: Integration of Web 2.0 Applications and Content Management Systems," In Proceedings of 11th European Conference on Knowledge Management, ECKM, Vol. 2, pp.1171-1177, 2010.

[18] L. Malita, "E-portfolios in an educational and occupational context. Procedia - Social and Behavioral Sciences", 1(1), 2312 2316.pp. 2009.

[19] Ellis, K Ryann., "Field Guide to Learning Management Systems,” ASTD Learning Circuits, 2009. 
[20] H. Barret, "Electronic Portfolios in STEM - What is an Electronic Portfolio," [Online]. Available: http://www.scribd.com/ doc/40206175/E-Portfolio-Definition

[21] JISC, "Effective Practice with e-Portfolios: Supporting 21st century learning," [Online]. Available: http://www.jisc.ac.uk/media/ documents/publications/effectivepracticeeportfolios.pdf

[22] Leap2ASpecification, website. [Online]. Available: http://wiki.cetis.ac.uk/LEAP2A_specification

[23] MoodleRepositoryAPI, website. [Online]. Available:http://docs.moodle.org/en/Development:Repository_API

[24] MoodlePortfolioAPI, website. [Online]. Available:http://docs.moodle.org/en/Development:Portfolio_API

[25] (2010) IMSBasicLearning ToolsInteroperabilitySpecification-V.1.0FinalSpecification. $\quad$ website. [Online]. Available:http://www.imsglobal.org/lti/blti/bltiv1 p0/ ltiBLTIimgv1 p0.html

[26] The Portfolio Interoperability Prototyping Project $\quad$ (PIOP), website.[Online]. Available:http://wiki.cetis.ac.uk/Portfolio interoperability prototyping

[27] C. Alario,S. Wilson, "Comparisonofthemainalternativestotheintegrationof externaltoolsindifferentplatforms,"ICERI2010Proceedings,pp. 3466-3476, 2010.

[28] R. Queirós, L.Oliveira, M. Pinto, \&C. Silva, “Towards e-Learning2.0:Case Study ofane-Learning Environment," InProceedings ofthe9thEuropeanConference oneLearning(ECEL2010),Instituto Superior deEngenhariadoPorto, Portugal,pp. 812-815,2010.

[29] J. Amsdem, "LevelsofIntegration-FivewaysyoucanintegratewiththeEclipse Platform," [Online]. Available: http://www.eclipse.org/articles/Article-Levels-Of-Integration/levels-of- integration.html

[30] T. Gilbert, "PearsonEducation: Leveraging SakaiandIMSLTItostandardize integrations,"10thSakaiConference- Boston,Mass.2009.

[31] M. Aitdaoud, et al. (2014). "ISIFePortfolio," [Online]. Available : http://maarifcentre.ma/eportfolio/.

[32] W. Hentzen, "Corn Explained," [Online]. Available : http://www.hentzenwerke.com/wp/cron_explained.pdf.

[33] Nadia Chafiq, Assia Benabid, Mohammed Bergadi, Bouzekri Touri, Mohammed Talbi, Laurent Lima, Advantages and Limits of the Implementation of Blended Learning for Development of Language Skills in Scientific Students, Original Research Article, Procedia - Social and Behavioral Sciences, Volume 116, 21 February 2014, Pages 1546-1550

[34] El Miloudi Belhaddioui, Noureddine Knouzi, Bouzekri. Touri, Mohammed Talbi, Current Situation on Organizational Knowledge Management, Organization and Governance, Original Research Article, Procedia - Social and Behavioral Sciences, Volume 116, 21 February 2014, Pages 1338-1342

[35] Bouzekri Touri, Insufficient Language Prerequisites: The Impact on College Students' Scientific Content Acquisition and Employment Market Requirements in Morocco, Original Research Article, Procedia - Social and Behavioral Sciences, Volume 82, 3 July 2013,Pages 663-667 